\title{
The Influence of Patient's Consciousness Regarding High Blood Pressure and Patient's Attitude in Face of Disease Controlling Medicine Intake
}

\author{
Maria Aparecida A Moura Strelec, Angela M. G. Pierin e Décio Mion Jr. \\ São Paulo, SP - Brazil
}

\begin{abstract}
Objective - To assess the relation between blood pressure control and the following: the Morisky-Green test, the patient's consciousness regarding high blood pressure, the patient's attitude in face of medicine intake, the patient's attendance at medical consultations, and the subjective physician's judgment.
\end{abstract}

Methods - We studied 130 hypertensive patients with the following characteristics: $73 \%$ females, $60 \pm 11$ years, $58 \%$ married, $70 \%$ white, $45 \%$ retired, $45 \%$ with incomplete elementary schooling, 64\% had a familial income of 1 to 3 minimum wages, body mass index of $30 \pm 7 \mathrm{~kg} / \mathrm{m}^{2}$, consciousness regarding the disease for a mean period of $11 \pm 9.5$ years, and mean treatment duration of $8 \pm 7$ years.

Results - Only 35\% of the hypertensive individuals had blood pressure under control and a longer duration of treatment $(10 \pm 7$ vs $7 \pm 6.5$ years; $P<0.05)$. The retiree predominated. The result of the Morisky-Green test did not relate to blood pressure control. In evaluating the attitude in face of medicine intake, the controlled patients achieved significantly higher scores than did the noncontrolled patients $(8 \pm 1.9$ vs $7 \pm 2, P<0.05)$. The hypertensive patients had higher levels of consciousness regarding their disease and its treatment, and most (70\%) patients attended 3 or 4 medical consultations, which did not influence blood pressure control. The physicians attributed significantly higher scores regarding adherence to treatment to controlled patients $(6 \pm 0.8$ vs $5 \pm 1.2 ; P<0.05)$.

Conclusion - Consciousness regarding the disease, the Morisky-Green test, and attendance to medical consultations did not influence blood pressure control.

Key words: hypertension, control, adherence, treatment

Nursing and Medical Schools of USP

Mailing address: Décio Mion Jr. - Instituto Central do HC

Av. Dr. Eneas C. Aguiar, 255, $7^{\circ}$, S/7032 - Cep 05403-900 - São Paulo, SP

Brazil - Email: deciomion@uol.com.br

English version by Stela Maris C. e Gandour
Hypertension is a serious public health problem due to its high prevalence, affecting $15 \%$ to $20 \%$ of the adult population and more than $50 \%$ of the elderly ${ }^{1}$. In addition, along with smoking, diabetes, and dyslipidemia, it is an important risk factor for cardiovascular diseases, which account for $30 \%$ of all deaths ${ }^{2}$.

The major objective of the antihypertensive treatment is to reduce cardiovascular morbidity and mortality ${ }^{3,4}$. Despite the effectiveness of antihypertensive treatment, high blood pressure is rarely controlled. Studies carried out among us have shown that approximately one third of patients had blood pressure under control ${ }^{5,6}$. Therefore, lack of blood pres sure control is a challenge to health care professionals. Several factors interfere with adherence to treatment ${ }^{7}$, among which are the patient's consciousness regarding the disease and the patient's behavior in face of medicine intake. In this regard, Morisky and Green ${ }^{8}$ proposed a self-reporting measure of medication adherence, the Morisky-Green test, composed of 4 questions to identify attitudes and behaviors in face of medication intake, which have proved useful for identifying patient's adherence to treatment.

Although self-reported information may be subject to problems, such as omission, lack of memory, and flaws in the communication process, this method is still widely used in studies, due to its important correlations with other methods ${ }^{9}$. Until the present time, the Morisky-Green test to evaluate control and adherence to treatment of hypertensive patients has not been reported among us. In addition, the study of the influence of consciousness and attitudes reported by hypertensive patients in regard to the bloodpressure-controlling medicamentous treatment is considered relevant. This study aimed at assessing the relation between blood pressure control and the following: (a) the Morisky-Green test; (b) the patient's consciousness regarding the disease and its treatment; (c) the patient's attitude in face of medication intake; (d) the attendance at medical consultations; (e) the physician's opinion.

\section{Methods}

This is an exploratory descriptive study with a quanti- 
tative approach that included 130 patients with mild or moderate primary high blood pressure (diastolic blood pressure between 90 and $109 \mathrm{mmHg}$, or systolic blood pressure between 140 and $179 \mathrm{mmHg}$, or both), aged more than 18 years, and with no associated diseases, such as acute myocardial infarction, stroke, renal diseases, and diabetes mellitus. The patients who had been undergoing treatment for at least 6 months agreed to take part in the study and signed the written informed consent. The study was approved by the Committee on Ethics.

The hypertensive patients were interviewed after medical consultation and answered the questions from the Morisky-Green test and 2 questionnaires, 1 about the attitudes regarding medicine intake and the other about patient's consciousness regarding the disease and its treatment.

The Morisky-Green test consists of the following questions: (1) have you ever forgotten to take your medicine? (2) are you sometimes neglectful in regard to your medicine hours? (3) do you skip your medicine hours when you are feeling well? (4) when you feel badly due to the medicine, do you skip it? According to the protocol of the Morisky-Green test ${ }^{8}$, patients are considered adherent to the treatment when they obtain the maximum score of 4 points, and patients are considered nonadherent when they obtain 3 points or less.

A questionnaire comprising 10 questions to assess the patient's attitude in regard to medicamentous treatment was also used, and 1 point was attributed to each expected positive attitude. Consciousness regarding the disease and its treatment was also assessed using 10 true-false questions, and 1 point was attributed to each true response.

The values written in the patients' medical records were used for blood pressure analysis. Routinely, blood pressure is measured with the patient seated after a 5-minute rest, with a calibrated aneroid device. The patients with the mean systolic and diastolic blood pressure values $<140 \mathrm{mmHg}$ and $<90 \mathrm{mmHg}$ respectively in the preceding 6 months were considered controlled hypertensive patients.

The classification of the hypertensive patient's adherence to treatment, according to the physician's opinion, was evaluated by attributing grades, which ranged from 1 to 7 , and by classifying the patient's adherence as total, partial, or null.

The responses obtained in the 3 processes were compared with blood pressure, and with the sensitivity, specificity, and accuracy of each question. The association between the classifying variables was assessed with the chi-square test, the likelihood ratio, or the Fisher exact test. The continuous variables were presented in tables containing the means and standard deviations observed in a single condition and analyzed with the Student $t$ test or the Wilcoxon rank sum test. Values of $\mathrm{P}<0.05$ were considered significant.

\section{Results}

Of the 130 patients studied, only $35 \%$ had their blood pressure controlled ( $<140 / 90 \mathrm{mmHg}$ ), $23 \%$ had stage I (mild) hypertension, 24\% had stage II (moderate) hypertension, $17 \%$ had isolated systolic hypertension, and $1 \%$ had stage III (severe) hypertension.
In regard to biosocial characteristics, lifestyle, duration of disease and treatment, table I shows that only occupation and duration of treatment significantly influenced $(\mathrm{P}<0.05)$ blood pressure control. The retirees and housewives were those who better controlled their blood pressure. The controlled hypertensive patients had longer treatment duration than the noncontrolled hypertensive patients ( $10 \pm 7$ vs $7 \pm 6.5$ years; $P<0.05$ ). The blood pressure levels of noncontrolled patients were significantly more elevated then those of the controlled patients.

Table II shows the results of the Morisky-Green test. Considering all hypertensive patients studied and the 4 questions assessed, the greatest percentages of positive attitudes regarding medication intake were: "not skipping the medication even when feeling badly" (83\%), and "not skipping the medication when feeling well" (72\%). Only the question about neglecting the medicine hours was significantly $(\mathrm{P}<0.05)$ associated with blood pressure control or lack thereof, ie, noncontrolled patients were more neglectful in regard to their medicine hours $(74 \%)$ than were controlled patients $(26 \%)$.

The addition of the points of controlled and noncontrolled hypertensive patients, according to recommendations in the Morisky-Green test, showed that $77 \%$ had a score $\leq 3$, and, therefore, were nonadherent. Blood pressure control did not significantly influence that classification. The total of positive attitudes regarding medicine intake analyzed according to the Morisky-Green test had a satisfactory specificity (70\%), revealing the proportion of noncontrolled patients with a negative attitude in the total of patients with noncontrolled blood pressure. Sensitivity, however, was low (39\%), showing the relation between the individuals with controlled blood pressure and a positive attitude regarding medicine intake and the total of hypertensive patients with controlled blood pressure. Considering a $59 \%$ accuracy, one can conclude that the Morisky-Green test was not efficient in relating blood pressure control to a positive attitude regarding medication intake.

In addition to the Morisky-Green test, another questionnaire was used aiming at assessing the attitudes regarding medication intake. Table III shows the significant percentage of patients with positive attitudes. Only the question regarding medication intake, even when blood pressure was controlled, was associated with blood pressure control. More noncontrolled patients reported neglecting medication intake than controlled patients did ( $83 \%$ vs $17 \% ; \mathrm{P}<0.05)$. Of the total of 10 questions, 6 responses had satisfactory sensitivity (>70\%), but only the question "taking note of time of medicine intake" had a satisfactory specificity $(76 \%)$.

Considering the 10 questions assessing the positive attitudes regarding medication intake, the mean score was significantly more elevated in controlled patients than in noncontrolled patients $(8 \pm 1.9$ vs $7 \pm 2 ; \mathrm{P}<0.05)$. When the cutoff point was 7 , a significant, although inverse, relation was observed, with a greater percentage of noncontrolled patients in the score range $\leq 7$ as compared with that of controlled patients $(73 \%$ vs $27 \%$; $\mathrm{P}<0.05)$. 


\begin{tabular}{|c|c|c|c|c|c|c|}
\hline \multirow[b]{3}{*}{ Characteristics } & \multicolumn{4}{|c|}{$\begin{array}{c}\text { yypertensive patients ac } \\
\text { and data on disease } \\
\text { Group }\end{array}$} & & \\
\hline & \multicolumn{2}{|c|}{$\overline{\text { Controlled }(\mathrm{n}=46)}$} & \multicolumn{2}{|c|}{ Noncontrolled $(\mathrm{n}=84)$} & \multicolumn{2}{|c|}{ Total $(n=130)$} \\
\hline & $\mathrm{N}$ & $\%$ & $\mathrm{~N}$ & $\%$ & $\mathrm{~N}$ & $\%$ \\
\hline \multicolumn{7}{|l|}{ Sex } \\
\hline Male & 11 & 31 & 24 & 69 & 35 & 27 \\
\hline Female & 35 & 37 & 60 & 63 & 95 & 73 \\
\hline \multicolumn{7}{|l|}{ Marital status } \\
\hline Single & 3 & 37 & 5 & 63 & 8 & 6 \\
\hline Married & 26 & 34 & 50 & 66 & 76 & 58 \\
\hline Widow(er) & 12 & 43 & 16 & 57 & 28 & 22 \\
\hline Separated & 2 & 33 & 4 & 67 & 6 & 5 \\
\hline Common law & 3 & 25 & 9 & 75 & 12 & 9 \\
\hline \multicolumn{7}{|l|}{ Race } \\
\hline Caucasian & 35 & 38 & 56 & 62 & 91 & 70 \\
\hline Noncaucasian & 11 & 28 & 28 & 72 & 39 & 30 \\
\hline \multicolumn{7}{|l|}{ Occupation * } \\
\hline Retiree & 26 & 45 & 32 & 55 & 58 & 45 \\
\hline Housewife & 18 & 37 & 30 & 63 & 48 & 37 \\
\hline Independent occupation & 0 & 0 & 10 & 100 & 10 & 8 \\
\hline Unemployed & 1 & 14 & 6 & 86 & 7 & 5 \\
\hline Others & 0 & 0 & 2 & 100 & 2 & 1 \\
\hline \multicolumn{7}{|l|}{ Educational level } \\
\hline Illiterate & 9 & 33 & 18 & 67 & 27 & 21 \\
\hline Literate & 7 & 25 & 21 & 75 & 28 & 21 \\
\hline Complete elementary schooling & 5 & 50 & 5 & 50 & 10 & 8 \\
\hline Incomplete elementary schooling & 22 & 38 & 36 & 62 & 58 & 45 \\
\hline Incomplete high schooling & 3 & 60 & 2 & 40 & 5 & 4 \\
\hline University education & 0 & 0 & 2 & 100 & 2 & 1 \\
\hline \multicolumn{7}{|l|}{ Family income (minimum wage) } \\
\hline$<1$ & 2 & 100 & 0 & 0 & 2 & 1 \\
\hline 1 to 3 & 29 & 34 & 57 & 66 & 86 & 64 \\
\hline 4 to 5 & 4 & 22 & 14 & 78 & 18 & 14 \\
\hline 5 to 7 & 7 & 58 & 5 & 42 & 12 & 9 \\
\hline 7 to 10 & 1 & 20 & 4 & 80 & 5 & 4 \\
\hline$>10$ & 3 & 50 & 3 & 50 & 6 & 5 \\
\hline Use of hormones & 2 & 50 & 2 & 50 & 4 & 3 \\
\hline Smoking & 1 & 10 & 9 & 90 & 10 & 8 \\
\hline Alcoholic beverages & 3 & 33 & 6 & 67 & 9 & 7 \\
\hline Physical activity & 16 & 41 & 23 & 59 & 39 & 30 \\
\hline Age & \multicolumn{2}{|c|}{$60 \pm 12$} & \multicolumn{2}{|c|}{$59 \pm 11$} & \multicolumn{2}{|c|}{$60 \pm 11$} \\
\hline Hypertension duration & \multicolumn{2}{|c|}{$12 \pm 9$} & \multicolumn{2}{|c|}{$10 \pm 9.5$} & \multicolumn{2}{|c|}{$11 \pm 9.5$} \\
\hline Treatment duration* & \multicolumn{2}{|c|}{$10 \pm 7$} & \multicolumn{2}{|c|}{$7 \pm 6.5$} & \multicolumn{2}{|c|}{$8 \pm 7$} \\
\hline BMI $\left(\mathrm{Kg} / \mathrm{m}^{2}\right)$ & \multicolumn{2}{|c|}{$29 \pm 6$} & \multicolumn{2}{|c|}{$30 \pm 7$} & \multicolumn{2}{|c|}{$30 \pm 7$} \\
\hline $\mathrm{SBP} / \mathrm{DBP}(\mathrm{mm} \mathrm{Hg})$ & \multicolumn{2}{|c|}{$127 \pm 7 / 79 \pm 5$} & 150 & $3 \pm 7 *$ & 142 & $38 \pm 9$ \\
\hline
\end{tabular}

\begin{tabular}{|c|c|c|c|c|c|c|c|c|c|}
\hline & \multicolumn{4}{|c|}{ Group } & & & \multirow{3}{*}{ Sensitivity $\%$} & \multirow{3}{*}{ Specificity $\%$} & \multirow{3}{*}{ Accuracy \% } \\
\hline & \multicolumn{2}{|c|}{ Controlled } & \multicolumn{2}{|c|}{ Noncontrolled } & \multicolumn{2}{|c|}{ Total } & & & \\
\hline & $\mathrm{n}$ & $\%$ & $\mathrm{n}$ & $\%$ & $\mathrm{n}$ & $\%$ & & & \\
\hline \multicolumn{10}{|c|}{ Forgets to take the medicine } \\
\hline Yes & 20 & 31 & 44 & 69 & 64 & 49 & 57 & 52 & 54 \\
\hline No & 26 & 39 & 40 & 61 & 66 & 51 & & & \\
\hline \multicolumn{10}{|c|}{ Skips medicine hours } \\
\hline Yes & 15 & 26 & 43 & $74 *$ & 58 & 45 & 67 & 51 & 53 \\
\hline No & 31 & 43 & 41 & 57 & 72 & 55 & & & \\
\hline \multicolumn{10}{|c|}{ Feels well and skips the medicine } \\
\hline Yes & 11 & 30 & 26 & 70 & 37 & 28 & 76 & 31 & 47 \\
\hline No & 35 & 38 & 58 & 62 & 93 & 72 & & & \\
\hline \multicolumn{10}{|c|}{ Feels badly and skips the medicine } \\
\hline Yes & 8 & 37 & 14 & 63 & 22 & 17 & 39 & 70 & 59 \\
\hline No & 38 & 35 & 70 & 65 & 108 & 83 & & & \\
\hline
\end{tabular}


Table III - Distribution of controlled and noncontrolled hypertensive patients according to the responses obtained in the questionnaire to assess patient's attitude in face of medicine intake, sensitivity, specificity, and accuracy

\begin{tabular}{|c|c|c|c|c|c|c|c|c|c|}
\hline & \multicolumn{4}{|c|}{ Group } & & & \multirow{3}{*}{ Sensitivity $\%$} & \multirow{3}{*}{ Specificity $\%$} & \multirow{3}{*}{ Accuracy $\%$} \\
\hline & \multicolumn{2}{|c|}{$\overline{\text { Controlled }}$} & \multicolumn{2}{|c|}{$\overline{\text { Noncontrolled }}$} & \multicolumn{2}{|c|}{ Total } & & & \\
\hline & $\mathrm{n}$ & $\%$ & $\mathrm{n}$ & $\%$ & $\mathrm{n}$ & $\%$ & & & \\
\hline \multicolumn{10}{|c|}{ Records medicine hours } \\
\hline Yes & 13 & 40 & 20 & 60 & 33 & 25 & 28 & 76 & 59 \\
\hline No & 33 & 34 & 64 & 66 & 97 & 75 & & & \\
\hline \multicolumn{10}{|c|}{ Takes medicine at the same hours } \\
\hline Yes & 29 & 34 & 57 & 66 & 86 & 66 & 63 & 32 & 43 \\
\hline No & 17 & 39 & 27 & 62 & 44 & 34 & & & \\
\hline \multicolumn{10}{|c|}{ Associates with activities } \\
\hline Yes & 26 & 39 & 41 & 61 & 67 & 52 & 57 & 51 & 53 \\
\hline No & 20 & 32 & 43 & 68 & 63 & 48 & & & \\
\hline \multicolumn{10}{|c|}{ Takes medicine when away from home } \\
\hline Yes & 37 & 37 & 64 & 63 & 101 & 78 & 80 & 24 & 44 \\
\hline No & 9 & 31 & 20 & 69 & 29 & 22 & & & \\
\hline \multicolumn{10}{|c|}{ Replaces medicine before running out } \\
\hline Yes & 38 & 35 & 70 & 65 & 108 & 83 & 83 & 17 & 40 \\
\hline No & 8 & 36 & 14 & 64 & 22 & 17 & & & \\
\hline \multicolumn{10}{|c|}{ Takes medicine on trips } \\
\hline Yes & 45 & 38 & 74 & 62 & 119 & 92 & 98 & 12 & 42 \\
\hline No & 1 & 9 & 10 & 91 & 11 & 8 & & & \\
\hline \multicolumn{10}{|c|}{ Takes medicine when $\mathrm{BP}$ is controlled } \\
\hline Yes & 39 & 44 & 50 & 56 & 89 & 68 & 85 & 40 & 56 \\
\hline No & 7 & 17 & 34 & $83 *$ & 41 & 32 & & & \\
\hline \multicolumn{10}{|c|}{ Does not take medicine with alcoholic ingestion } \\
\hline Yes & 4 & 29 & 10 & 71 & 14 & 11 & 91 & 12 & 40 \\
\hline No & 42 & 36 & 74 & 64 & 116 & 89 & & & \\
\hline \multicolumn{10}{|c|}{ Skipped medication in the last 30 days } \\
\hline Yes & 19 & 31 & 43 & 69 & 62 & 48 & 59 & 51 & 54 \\
\hline No & 27 & 40 & 41 & 60 & 68 & 52 & & & \\
\hline \multicolumn{10}{|c|}{ Missed consultation } \\
\hline Yes & 11 & 30 & 26 & 70 & 37 & 28 & 76 & 31 & 59 \\
\hline No & 35 & 38 & 58 & 62 & 93 & 72 & & & \\
\hline
\end{tabular}

Table IV shows that patients' consciousness regarding high blood pressure was satisfactory. Only in the following 2 questions was the percentage of correct answers lower than $50 \%$ : "high blood pressure is asymptomatic" (30\%) and "high blood pressure may be treated without medicine" $(11 \%)$. Sensitivity was satisfactory $(>70 \%)$ in 7 questions (chronic disease, complications, continuous treatment, physical activity, weight loss, reduction in salt ingestion, and nervousness), indicating the existence of sensitivity to associate consciousness regarding the disease and treatment with blood pressure control. However, only the following 2 questions showed satisfactory specificity: "hypertension is asymptomatic" and "high blood pressure may be treated without medicines."

Despite the high levels of consciousness regarding high blood pressure and its treatment, no association with blood pressure control was observed ( $\mathrm{P}>0.05)$, and this was also shown by the similar means obtained by the controlled and noncontrolled hypertensive patients $(7 \pm 1$ and $7 \pm 1.5$, respectively).

Analyzing attendance at medical consultations during 6 months, most patients ( $70 \%$ ) attended 3 or 4 consultations, $5 \%$ attended 6 consultations, and $10 \%$ attended only 2 consultations. No significant association between blood pressure control and the $n$ umber of consultations attended was observed.
In the assessment performed by the physicians regarding the patients' adherence to treatment, the grades attributed to controlled hypertensive patients were significantly higher than those attributed to noncontrolled hypertensive patients $(6 \pm 0.8$ vs $5 \pm 1.2, \mathrm{P}<0.05)$.

In regard to medicamentous treatment, a little over half $(56 \%)$ of the patients had been prescribed 2 antihypertensive medications, $26 \%$ one medication, and $18 \%$ three or more. The most frequently prescribed medications were diuretics in monotherapy or associated with drugs with a central action, angiotensin-converting enzyme inhibitors and calcium-channel antagonists. The patients who did not control blood pressure were prescribed a significantly greater number $(\mathrm{P}<0.05)$ of drugs than those who controlled blood pressure (tab. V).

\section{Discussion}

The present study showed that the hypertensive patients according to the Morisky-Green test reported positive attitudes in regard to medication intake; however, the association with blood pressure control or lack thereof was of little significance, except for the question "negligence in medication intake hours." The hypertensive patients had a satisfactory level of consciousness in regard to the disease 


\begin{tabular}{|c|c|c|c|c|c|c|c|c|c|}
\hline & \multicolumn{4}{|c|}{ Group } & \multirow{2}{*}{\multicolumn{2}{|c|}{ Total }} & \multirow{3}{*}{ Sensitivity \% } & \multirow{3}{*}{ Specificity $\%$} & \multirow{3}{*}{ Accuracy $\%$} \\
\hline & \multicolumn{2}{|c|}{ Controlled } & \multicolumn{2}{|c|}{$\overline{\text { Noncontrolled }}$} & & & & & \\
\hline & $\mathrm{n}$ & $\%$ & $\mathrm{n}$ & $\%$ & \multicolumn{2}{|c|}{$\mathrm{n} \%$} & & & \\
\hline \multicolumn{10}{|c|}{ High blood pressure is for a lifetime } \\
\hline True & 39 & 38 & 64 & 62 & 103 & 79 & 85 & 24 & 45 \\
\hline False & 7 & 26 & 20 & 74 & 27 & 21 & & & \\
\hline \multicolumn{10}{|c|}{ High blood pressure is asymptomatic } \\
\hline True & 19 & 46 & 22 & 54 & 41 & 32 & 41 & 74 & 62 \\
\hline False & 27 & 30 & 62 & 70 & 89 & 68 & & & \\
\hline \multicolumn{10}{|c|}{ High blood pressure is $140 / 90$} \\
\hline True & 26 & 36 & 46 & 64 & 72 & 55 & 57 & 45 & 49 \\
\hline False & 20 & 34 & 38 & 66 & 58 & 45 & & & \\
\hline \multicolumn{10}{|c|}{ High blood pressure has complications } \\
\hline True & 43 & 35 & 80 & 65 & 123 & 95 & 93 & 5 & 36 \\
\hline False & 3 & 43 & 4 & 57 & 7 & 5 & & & \\
\hline \multicolumn{10}{|c|}{ High blood pressure treatment is for a lifetime } \\
\hline True & 43 & 39 & 68 & 61 & 111 & 85 & 93 & 19 & 43 \\
\hline False & 3 & 16 & 16 & 84 & 19 & 15 & & & \\
\hline \multicolumn{10}{|c|}{ High blood pressure may be treated without medicine } \\
\hline True & 6 & 40 & 9 & 60 & 15 & 11 & 13 & 89 & 62 \\
\hline False & 40 & 35 & 75 & 65 & 115 & 89 & & & \\
\hline \multicolumn{10}{|c|}{ Physical activity controls blood pressure } \\
\hline True & 33 & 34 & 63 & 66 & 96 & 74 & 72 & 25 & 42 \\
\hline False & 13 & 38 & 21 & 62 & 34 & 26 & & & \\
\hline \multicolumn{10}{|c|}{ Weight loss controls blood pressure } \\
\hline True & 38 & 36 & 69 & 64 & 107 & 82 & 83 & 18 & 41 \\
\hline False & 8 & 35 & 15 & 65 & 23 & 18 & & & \\
\hline \multicolumn{10}{|c|}{ Salt reduction controls blood pressure } \\
\hline True & 45 & 35 & 82 & 65 & 127 & 98 & 98 & 2 & 36 \\
\hline False & 1 & 33 & 2 & 67 & 3 & 2 & & & \\
\hline \multicolumn{10}{|c|}{ Nervousness reduction controls blood pressure } \\
\hline True & 44 & 35 & 82 & 65 & 126 & 97 & 96 & 2 & 35 \\
\hline False & 2 & 50 & 2 & 50 & 4 & 3 & & & \\
\hline
\end{tabular}

\begin{tabular}{|c|c|c|c|c|c|c|}
\hline \multicolumn{7}{|c|}{$\begin{array}{l}\text { Table V - Distribution of controlled and noncontrolled hypertensive } \\
\text { patients and the number of medicines prescribed }\end{array}$} \\
\hline \multirow{3}{*}{ N. of drugs } & \multicolumn{4}{|c|}{ Group } & \multirow{2}{*}{\multicolumn{2}{|c|}{ Total }} \\
\hline & \multicolumn{2}{|c|}{$\overline{\text { Controlled }}$} & \multicolumn{2}{|c|}{ Noncontrolled* } & & \\
\hline & $\mathrm{n}$ & $\%$ & $\mathrm{n}$ & $\%$ & \multicolumn{2}{|r|}{$\%$} \\
\hline 1 & 18 & 53 & 16 & 47 & 34 & 26 \\
\hline 2 & 20 & 27 & 53 & 73 & 73 & 56 \\
\hline$\geq 3$ & 7 & 30 & 16 & 70 & 23 & 18 \\
\hline Total & 45 & 35 & 85 & 65 & 130 & 100 \\
\hline$* p<0.05$ & & & & & & \\
\hline
\end{tabular}

and its treatment and a weak association with blood pressure control or lack thereof. It is worth noting, however, that in a more comprehensive evaluation with more questions about the attitude regarding medicamentous treatment, a significant relation between the score obtained and blood pressure control was observed. Therefore, the MoriskyGreen test and consciousness about the disease and its treatment did not have enough comprehensiveness to foretell blood pressure control. In this study, the evaluation of hypertensive patients with the already cited test was limited to a specific point and performed during the treatment, which may justify the results found.

Only approximately one third of the hypertensive patients studied had blood pressure under control, similarly to that reported in the literature ${ }^{6,7,10}$. The influence of retire- ment and a longer treatment period of blood pressure control could be justified by the greater availability of dedication to treatment. Studies have shown that a more advanced age, a low educational level, a low income, and less than 5 years of disease duration are associated with abandonment of treatment and inadequate blood pressure control ${ }^{7,11}$.

Health professionals have tried to advise hypertensive patients about the importance of blood pressure control with or without medicamentous treatment.Healtheducation for hypertensive patients is relevant for success in controlling blood pressure ${ }^{12,13}$. Regarding the attitude of hypertensive patients in face of medicamentous treatment, some recommendations are part of the usual practice in an attempt to improve patient's adherence to treatment. In the present study, we tried to relate some of these recommendations to blood pressure control. Considering the positive responses of hypertensive patients, the results have shown that the total score coincided with the degree of blood pressure control as follows: patients with controlled blood pressure achieved significantly higher grades than those with noncontrolled blood pressure $(\mathrm{P}<0.05)$, although separately the questions did not relate to blood pressure control, except for 1 question.

It is worth noting that in the association of consciousness regarding the disease and its treatment with blood pressure control, also assessed in this study, the sa- 
tisfactory consciousness expressed by the hypertensive patients did not relate to blood pressure control. This may indicate that the hypertensive patients comprising the study sample, although expressing consciousness about important aspects of their disease and its treatment, did not sufficiently change their lifestyle to obtain blood pressure control. It is also worth emphasizing that consciousness is rational, while adherence to treatment is a complex process involving emotional factors and concrete barriers of practical and logistic order ${ }^{14,15}$.

Attendance at medical consultations may also be a parameter to assess adherence to treatment ${ }^{9}$, but in the present study it did not relate to blood pressure control or lack thereof.

The classification of the hypertensive patients' adherence carried out by the physicians showed an association with blood pressure control, thus revealing that physicians may know the situation of blood pressure control of their patients.
The findings in this study point towards the need for a multidisciplinary approach, in which each patient's experience, values, beliefs, and cultural practices are recognized and approached. As such, the social and psychosocial context of the patient should be considered. The involvement with health problems, expressed by positive attitudes and feelings, tends to favor adherence to treatment and consequent high blood pressure control, in addition to effective interaction with the multidisciplinary team in a process of mutual acceptance and respect ${ }^{16}$.

Our data have shown that, although the patients had positive attitudes in regard to medicamentous treatment and a good consciousness level regarding their disease and its treatment, blood pressure control was not satisfactory, characterizing the need for measures aiming at more effective blood pressure control, making the treatment a problem for everyone involved: the hypertensive patient, the family, the community, the institutions, and the health team.

\section{References}

1. IVDiretrizesBrasileirasde Hipertensão Arterial. Campos do Jordão, Soc. Bras. Hipertensão, Soc. Bras. Cardiologia, Soc. Bras. Nefrologia. 2002.

2. HametP. The burden of blood pressure: where are we and where should we go? Can Cardiol 2000;16:1483-7.

3. Joint National Committee on Prevention, Detection, Evaluation, and Treatment of High Blood Pressure, 6, Bethesda, MD, 1997. Report. Bethesda, MD, National Institute of Health, 1997. (NIH Publication, 98-4080).

4. World Health Organization International Society of Hypertension Guidelines for the Management of Hypertension 1999. J Hypertens 1999; 17:151-83.

5. Piccini RX, Victora CG. How well is hypertension managed in the community? A population-based survey in a Brazilian city. Cad Saude Publica 1997; 13:595-600.

6. FuchsFD, Fuchs SC, MoreiraLB, etal. Grau de conhecimentoe controle de hipertensão arterial sistêmica na população de Porto Alegre. Hipertensão 2001,4(suppl):9.

7. Pierin AMG, Mion JR D, Fukushima J, Pinto AR, Kaminaga M. O perfil de um grupo de pessoas hipertensas de acordo com conhecimento e gravidade da doença. Rev Esc Enf USP 2001;35:11-8.

8. Morisky DE, Green LW, Levine DM. Concurrent and predictive validity of a selfreported measure of medication adherence. Med Care 1986;24:67-73.

9. Homedes N, Ugalde A. Estudos sobre el cumplimiento del paciente en paises en desarollo. Bol Sanit Panam 1994;116:518-34.
10. National High Blood Pressure Education Program. Working group report on primary prevention of hypertension. Bethesda, MD, National Institute of Health, 1993. (NIH Publication, 93-2669).

11. Busnello RG, Melchior R, Faccin C, et al. Características associadas ao abandono do acompanhamento de pacientes hipertensos atendidos em um ambulatório de referência. Arq Bras Cardiol 2001; 76:349-51.

12. Contreras EM, Martinez CJJ, Pérez RJ, et al. Ensayo sobre la eficacia de los programas de educacion para la salud en el cumplimiento terapeutico de la hipertencion arterial. Aten Primaria 1998; 21:199-204.

13. Cuspidi C, Sampieri L, Macca G, et al. Improvement of patients' knowledge by a single educational meeting on hypertension. J Hum Hypertens 2001; 15:57-61.

14. Hasford J. Compliance and the benefit/risk relationship of antihypertensive treatment. J Cardiovasc Pharmacol 1992;20(suppl):30-4.

15. Pierin AMG. Adesão ao tratmento. In: Nobre F, Pierin A, Mion Jr D. Adesão ao Tratamento: O Grande Desafio da Hipertensão. São Paulo: Lemos Editorial, 2001.p.23-33

16. Lahdenpera TS, Kyngas HA. Levels of compliance shown by hypertensive patients and their attitude toward their illness. J Adv Nurs 2001;34:189-95. 